\title{
Analysis of Water Resistance Reference Methods
}

\author{
${ }^{1}$ Guzel R. Ganieva, ${ }^{2}$ Magtenbek R. Redjepov \\ ${ }_{1,2}$ Kazan Federal University \\ Email: GGuzelRafikovna@mail.ru
}

Received: 20 ${ }^{\text {th }}$ August 2019, Accepted: 30 ${ }^{\text {th }}$ September 2019, Published: 31 ${ }^{\text {st }}$ October 2019

\begin{abstract}
In this article, we analyze the existing methods for limiting water inflow in wells and the problems associated with them. The fields, their geological structure, fluid properties and geological exploration of the blocks under consideration were also considered and analyzed. To fully understand the problem, we analyzed the development status, the properties of polymers and their effect on additional production. Based on the analysis results of different articles, we made an approximate forecast until 2019 using polymer flooding.

The work purpose is to analyze the methods for limiting the water inflow introduced and used today. Many researchers have also set the goal of studying the application relevance of restriction methods. To achieve this goal, it is necessary to analyze, study the application effectiveness and the economic feasibility of the proposed method for limiting water inflow in the well. As an example, we considered and analyzed different measures to limit water inflow at a late stage of development.
\end{abstract}

Keywords

Geological and Technical Measures, Surfactants, Catalyst, Zeolite, Water Cut, Well.

\section{Introduction}

The purpose of this work is the forecast of additional development of deposits using geological and technical measures at a late stage [1]. To achieve this goal, it was necessary to analyze the following main issues and solve the following tasks:

1) to study the geological structure and oil content of the reservoir in question;

2) to study the geological and physical characteristics of the oil reservoir;

3) to consider and analyze the dynamics of the reagents used;

4) to study the properties of polymers;

5) to evaluate the technological efficiency of the use of polymers by the method;

6) to analyze patents on the limitation of water inflow;

7) to propose a new method of limiting water inflow based on a natural catalyst.

Today, the main problem in oil production is water cut [1]. Well watering leads to large losses of oil and gas, which negatively affects production, and therefore the economy. The researchers are actively working in this direction, but the results of applying new and previously known technologies for limiting water inflow are not $100 \%$ effective. This problem occurs due to a misunderstanding of the causes of water entering the wells and an incorrect selection of materials and technologies during repair and insulation works at the wells $[2,8]$.

Thus, the problem of water cut is inherent in both new and existing wells. Timely analysis of the manufacture and use of reagents to limit water inflow can be performed by modeling. A competent approach and a technologically correctly selected reagent effectively affect the studied object. After downloading, the reagent should create a blocking screen condition. The proposed approach shall achieve certain results after the measures are taken.

Progress is aimed at limiting the water flow into oil wells. The restriction is due to the implementation of waterproofing. Their main purpose is to isolate the water supply paths to the well in order to reduce the water cut of the produced products. The main method of waterproofing in oil wells is the injection of chemicals that can be filtered into a porous medium and plug the paths of water into the well [1,2].

An important role in limiting water inflow (insulating composition) is played by chemicals with various compositions. The selection and application of a specific composition, which will most effectively affect the necessary area, depends on the field, geological structure and reservoir productivity.

Exposure process.

1. Working raw materials (reagent) fill the space, and the channel of water passage; 2. 2. The working raw materials used shall have an effective effect as a barrier.

Physical and chemical composition of the proposed and used reagents:

The reagent used shall be active;

The reagent shall not have a negative effect on the soil and on working personnel due to its composition;

The reagent used shall be environmentally friendly in order to avoid negative consequences;

Working raw materials shall contain environmentally friendly materials;

The ecological composition of working raw materials shall be affordable and profitable to use from an economic point of view;

Due to its composition, the proposed reagent shall have an unlimited shelf life in the warehouse;

Universality (application in any season); 
Thus, to achieve this goal in the work, it is necessary to analyze studies of the use of various reagents. To identify the advantages and disadvantages of the proposed reagents. To study the composition, which is planned to be used as the main reagent composition. To analyze the use of the selected reagent under various conditions. The selected method shall meet the criteria, both in economics and in ecology.

\section{Methods}

In the course of work, we studied many works on oil recovery intensification. As the analysis result of the methods used to increase oil recovery, we considered the most cost-effective materials. As we know, the sedimentary and gel-forming reagents are expensive [3]. The goal of the researchers is to use the most profitable raw materials in the composition to solve many pressing issues related directly to waste in the petrochemical industry. An economically sound solution is the use of recycled material for the manufacture of the necessary raw materials. This approach positively affects not only the economic problem, but also the environmental one. A difficult situation in the process of storage or disposal of industrial waste negatively affects the environment. In work []ㅡ, the authors investigated the aluminosilicate - GOS "Zeolite", which meets all the above requirements [4].

The proposed method differs from the rest (applied) in that the gel is formed directly in the reservoir after injection following a certain time. The advantage of this method is that the proposed reagent can be used at any time of the year without limitation. There is also no need for special training. Thus, the relevance of the analyzed method lies in simplicity [2].

\section{Results and Discussion}

The situation of water cut is one of the global problems in the oil and gas industry. As can be seen from the practice and analysis of many works, the use of gel components is effective. The most used active and economic component in raw materials is silicon. The gel-forming compositions based on various chemicals are also known. Polymers and silicates are used as reagents [4].

In the work [ 5 ], the authors propose using hydrochloric acid, water, and a nepheline-based gelling liquid as part of the liquid. The proposed method has several disadvantages. The gelling rate is actively influenced by the substance used as part of the working mixture. This component affects the gelling rate. Thus, it is achieved technical result and composition effectiveness increasing by:

- regulation of gelling time,

- regulation of viscosity;

- increasing the structure strength;

- solution of an environmental problem.

The main advantage of this approach is the disposal of petrochemical production waste $[4,6]$.

The gel-forming compositions obtained by the proposed method are characterized by low-viscosity fluids that are easily filtered in the liquid collector [6]. The new gelling compositions are made on the basis of zeolite catalysts and acids rejected in the production, in other words, the remains of a petrochemical production.

The authors of the work analyzed the necessary composition of the rejected zeolite catalyst. Zeolite is the main raw material in the reagent, which affects the dynamic viscosity. A decrease in the zeolite amount in the reagent composition leads to a change in the strength of the manufactured raw materials.

As a result of the analyzed work, it follows that the reagent thus prepared has high filterability; due to the gel structure, it has the ability to penetrate deeply; gelling composition contributes to uniform coverage of the collectors; this composition, due to the zeolite content in its content, has also a good water-insulating property. The main advantage of this method is the ease of reagent manufacture, which does not require special devices and preliminary preparation of raw materials. This preparation condition also does not require separate transportation of all components included in the composition of the raw materials, which facilitates the issue of transportation, storage at the facilities and introduction into production. The use of secondary raw materials to obtain a marketable product also positively affects the environment. This approach allows resolving the issue of waste management in the petrochemical industry

Due to the active use of zeolite in the composition of the catalysts, the ecological and economic situation is solved in order to protect the environment [7].

\section{Summary}

The cited materials indicate that, despite all environmental measures, the state of the environment is on the verge of an environmental disaster [7]. Improvement of the efficiency of reserves development remains an urgent task for many manufacturers. Constant monitoring of MAC (maximum allowable concentrations) and ALL (allowable load limit) contributes to continuous monitoring of various types of pollution of water, soil and atmosphere. Compliance with elementary requirements, instructions and orders may exclude an emergency condition at the fields $[9,10]$.

Thus, the measures taken to protect the environment minimize the risk of damage from the operation of emergency situations in the fields [1].

With the condition that many fields are at a late stage of development, which entails a low debit of wells, the use of gelforming compounds is very widely spread. Since this reagent allows creating a strong waterproofing barrier in its composition, it allows creating a stable long exposure time. This reagent is selected subject to the features of the geological structure of the reservoir. The environmental friendliness of the reagent used is that it contains zeolite. Zeolite is both an 
absorbent and an adsorbent in its composition. By its chemical and physical composition, zeolite can be divided into volcanic, sedimentary and synthetic rock. The main difference between the zeolites described is the temperature indicator and the content of aluminosilicates in their composition. The higher the hardness index is, the stronger the material is. Zeolite also varies in composition and depends on the deposit. Tables 1-6 show the physicochemical characteristics of the zeolite.

\begin{tabular}{|c|c|}
\hline Mineral & \% weight \\
\hline Clinothylolite & $20-30$ \\
\hline Montmorillonite & $20-30$ \\
\hline Opal cristobalite & $28.0-36.7$ \\
\hline Calcite & $10.6-21$ \\
\hline Quartz & $4.6-11.3$ \\
\hline
\end{tabular}

Table 1: Mineral Composition

\begin{tabular}{|c|c|}
\hline Oxides & \% weight \\
\hline $\mathrm{SiO}_{2}$ & 65.88 \\
\hline $\mathrm{TiO}_{2}$ & 0.35 \\
\hline $\mathrm{Al}_{2} \mathrm{O}_{3}$ & 6.19 \\
\hline $\mathrm{Fe}_{2} \mathrm{O}_{3}$ common. & 2.65 \\
\hline $\mathrm{MnO}$ & $<0.01$ \\
\hline $\mathrm{CaO}$ & 17.16 \\
\hline $\mathrm{MgO}$ & 1.45 \\
\hline $\mathrm{Na}_{2} \mathrm{O}$ & 0.16 \\
\hline $\mathrm{K}_{2} \mathrm{O}$ & 1.43 \\
\hline $\mathrm{P}_{2} \mathrm{O}_{5}$ & 0.13 \\
\hline
\end{tabular}

Table 2: Chemical Composition

\begin{tabular}{|c|c|}
\hline Appearance & Light gray, white granules \\
\hline Smell & not \\
\hline Porosity & $37.25-55.72 \%$ \\
\hline Density & $2,03-2,37 \mathrm{~g} / \mathrm{cm}^{3}$ \\
\hline \multicolumn{2}{|c|}{ Mechanical crush strength } \\
\hline At $20^{\circ} \mathrm{C}$ & $46 \mathrm{~kg} / \mathrm{cm}^{2}$ \\
\hline At $250^{\circ} \mathrm{C}$ & $59 \mathrm{~kg} / \mathrm{cm}^{2}$ \\
\hline vibration wear & $0,96 \%$ \\
\hline Bulk density, $\mathrm{g} / \mathrm{cm}^{3}$ & $0.4-0.8$ \\
\hline bulk mass, $\mathrm{g} / \mathrm{cm}^{3}$ & 1,10 \\
\hline Effective Pore Diameter & $0,4 \mathrm{~nm}(4 \AA)$ \\
\hline \multicolumn{2}{|c|}{$\begin{array}{l}\mathrm{P} / \mathrm{P}_{\mathrm{S}}=0,11-2,5 \% \\
\mathrm{P} / \mathrm{Ps}=0,47-4,5 \% \\
\mathrm{P} / \mathrm{Ps}=0,98-20,4 \%\end{array}$} \\
\hline Dynamic moisture capacity & $3,8 \%$ \\
\hline Dew point & $-44^{\circ} \mathrm{C}$ \\
\hline
\end{tabular}

Zeolite of volcanic sedimentary origin

Table 3: Physical Properties

\begin{tabular}{|c|c|}
\hline Clinoptilolite & no less $70 \%$ \\
\hline Montmorillonite & $2-4 \%$ \\
\hline Quartz & At $10 \%$ \\
\hline Plagioclase & $5-10 \%$ \\
\hline Carbonate & $3 \%$ \\
\hline Hydromica & $1-3 \%$ \\
\hline
\end{tabular}

Table 4: Mineral Composition 


\begin{tabular}{|c|c|}
\hline $\mathrm{SiO}_{2}$ & $65,0-71,3 \%$ \\
\hline $\mathrm{Al}_{2} \mathrm{O}_{3}$ & $11,5-13,1 \%$ \\
\hline $\mathrm{CaO}$ & $2,7-5,2 \%$ \\
\hline $\mathrm{K}_{2} \mathrm{O}$ & $2.2-3.4 \%$ \\
\hline $\mathrm{Fe}_{2} \mathrm{O}_{3}$ & $0,7-1,9 \%$ \\
\hline $\mathrm{MgO}$ & $0,6-1,2 \%$ \\
\hline $\mathrm{Na}_{2} \mathrm{O}$ & $0,2-1,3 \%$ \\
\hline $\mathrm{TiO}_{2}$ & $0,1-0,3 \%$ \\
\hline $\mathrm{MnO}$ & 0,04 \\
\hline $\mathrm{P}_{2} \mathrm{O}_{5}$ & 0.02 \\
\hline $\mathrm{ratio}: \mathrm{Si} / \mathrm{Al}$ & $4.8-5.4$ \\
\hline
\end{tabular}

Table 5: Chemical Composition

\begin{tabular}{|c|c|}
\hline Appearance & The granules are light gray; white color \\
\hline Smell & not \\
\hline Porosity & $38-46 \%$ \\
\hline Density & $2,2-2,3 \mathrm{~g} / \mathrm{cm}^{3}$ \\
\hline \multicolumn{2}{|c|}{ Mechanical strength } \\
\hline Abrasion & not more than $0,32-0,5 \%$ \\
\hline Grindability & not more than $0,62-1,86 \%$ \\
\hline Mohs hardness & $3.5-4$ \\
\hline Bulk mass & $1040-1080 \mathrm{~g} / \mathrm{cm}^{3}$ \\
\hline Effective pore diameter & $0,4 \mathrm{~nm}(4 \AA)$ \\
\hline PH value & $6.8-7.2$ \\
\hline Water adsorption capacity & $34-38 \%$ \\
\hline Macropore area & $18-21 \mathrm{~m}^{2} / \mathrm{g}$ \\
\hline Micropore area & $1-2 \mathrm{~m}^{2} / \mathrm{g}$ \\
\hline Hydration temperature & $270-300{ }^{\circ} \mathrm{C}$ \\
\hline Softening point & $1260^{\circ} \mathrm{C}$ \\
\hline Melting point & $1340{ }^{\circ} \mathrm{C}$ \\
\hline
\end{tabular}

Table 6: Physical Properties

According to organoleptic and physico-chemical indicators, water extracts obtained from natural zeolite shall comply with the Unified Sanitary and Epidemiological and Hygienic Requirements for Products [10].

\section{Conclusions}

In the work, we considered and analyzed modern methods of limiting water inflow. A competent analysis and a correct understanding of the problem of water cut contribute to an effective approach to solving the global problem.

It is necessary to use the injection of reagents that contribute to a significant increase in the layer permeability at the fields [1]

As a result of the analyzed work and costs, we calculated the approximate costs of isolation:

- Net profit amounted to 191.10 thousand manat per day;

- Economic effect amounted to 238.88 thousand manat.

According to the calculated approximate results, it is assumed that the proposed operation can pay off in 2 weeks of operation along the well with an oil production rate of 210 tons/day. The data are calculated on the example of the $\mathrm{X}$ field. For safe and stable operation, compliance with industrial safety is also necessary, without violating the basic requirements that may entail undesirable consequences. It is also necessary to comply with the requirements to eliminate accidents that may entail environmental consequences, which can lead to environmental disaster. As we know, the violation that led to the emergency as a result of this is pollution of the soil, groundwater and environment. The environmental situation in the country is also on the verge. Therefore, observing all the requirements, the use of proven (organic) compositions, in turn, may entail consequences that reduce the negative impact on the outside world.

Using the hydrodynamic model, it is possible to predict and simulate the process of pumping polymer solution [1].

\section{Acknowledgements}

The work is performed according to the Russian Government Program of Competitive Growth of Kazan Federal University. 


\section{References}

[1] Redzhepov M.R. Thesis

https://kpfu.ru/student_diplom/10.160.178.20_1301684_Diplomnaya_rabota_Redzhepova_Magtymbeka.R._11.0 6.19_.pdf

[2] Bulletin of the Perm University O.E. Kochneva, I.A. Endaltseva Causes and analysis of the water cut of the Bashkir-Serpukhov deposit of the Unvinsky oil field of the Solikamsk Depression Issue 3 Geology 2012).

[3] Mukhametshin N.M., Khasanov F.F. et al. Gel-forming composition for regulating the permeability of formations. - Patent of the Russian Federation No. 2291890 https://findpatent.ru/patent/229/2291890.html

[4] Ovsyukov A.V., Garifullin M.G., Maksimova T.N. The possibility of using gel-forming compositions based on a zeolite-containing component // Oilfield business. 1997. - No. 1. - P. 28-31.

[5] Mukhametzyanova R.S.; Enikeev R.M.; Fakhretdinov R.N. Method for the development of oilfields. Patent of the Russian Federation http://ru-patent.info/20/85-89/2089723.html

[6] Selimov F.A., Khayredinov N.Sh., Blinov S.A. et al. Gel-forming composition for regulating the permeability of formations https://findpatent.ru/patent/218/2181427.html C, 2012-2019

[7] Vasilenko V.A. Nature and economics: Challenges and searches for ways of sustainable development / Novosibirsk, 1997. -123 p.

[8] Ufa Scientific Center of the Russian Academy of Sciences https://www.delovoigorod.ru/ufa/info/uvelichenienefteotdachi-95/

[9] Panchenkov G.M. Chemical methods of dealing with flooding cones. Collection "Issues of oil production and drilling techniques in the fields of the Second Baku". Gostoptekhizdat. 1943, p. 108-112.

[10] A method for controlling the development of a heterogeneous time along an oil phase of a formation. Nazmiev I.M., Shaydullin F.D., Gallyamov I.M., Vakhitova A.G. https://findpatent.ru/patent/222/2224092.html

[11] SPARTA LLC. Minerals and active additives. TU 2163-001-27860096-2016, TU 2163-004-61604634-2013. 